\title{
Size and Decision-Making: a Systematic Literature Review on Groups and Teams
}

\author{
Besnik AVDIAJ ${ }^{1}$
}

DOI: $10.24818 / \mathrm{mer} / 2022.02-02$

\begin{abstract}
Groups have attracted the attention of scholars and researchers for a long time. Many studies have been conducted on group dynamics, characteristics, behaviour, group members relations, and how demographical aspect influences group work. This study focuses on how one of the main elements of group - the size - affects people's actions in terms of making decisions, with emphasis on teams. Conducting a systematic literature review on 68 studies which focus on group size effects from different perspectives, such as cultural, social, political, religious, educational, and organizational, it is revealed that most of the scholars propose that the smaller the groups are, the more effective they can be in performing common actions. However, this varies depending on the settings in which the teams operate. In this regard, sometimes large groups are more likely to be more productive than the small ones. When it comes to the organizational perspective of group size, the size effect in function of team success achievement has been considered. Studies suggest that teams are more likely to be successful when they grow in size. Yet, depending on what they do, there is an upper limit, after which, the size does not have any effect. In fact, it may even have a negative correlation - like an inverted U. Decision-making is a crucial process to reaching personal and collective goals. This process costs time and other resources, therefore, making it more effective is a never-ending ambition of organizations. This systematic literature review aims to analyze and synthetize the existing research work in the field and aggregate the so-far findings from different contexts in order to create a clear path for future research in this area. Conclusions suggest an optimal number of team members in different work settings which would benefit from effective decision-making. Future directions to scholars and recommendations to managers are given.
\end{abstract}

KEYWORDS: organization, organizational behaviour, decision making, behavioural, human resources, team

JEL CLASSIFICATION: D230, D810, D910, O150, M540

\section{INTRODUCTION}

The dynamic and complex environment of today is as a result of constant changes made by mankind during history. Today, we are facing uncertainty and low predictability of the effects of our actions. The complex environment we are used to know has begun getting complicated since mankind started thinking rationally. Krasniqi states in Avdiaj (2017) that the way a human thinks and lives is formed under the social and economic conditions, leading to stronger relations between people and the creation of groups. Nevertheless, the scientific study of functioning of groups lies late in our era, and today we are witnessing dramatic changes more and more often.

\footnotetext{
${ }^{1}$ University of Prishtina, Republic of Kosovo, besnik.avdiaj@studentet.uni-pr.edu
} 
Groups are established to have an impact. At this point, it is generally accepted that their influence is strongly affected by their size (Esteban \& Ray, 2001; Oliver \& Marwell, 1988). Having said that, group size and its effects have attracted researchers' attention really late, but it still keeps being a hot topic in the research field related to group processes.

As the purpose of this paper is the integrated analysis of studies which have addressed the group size, then to come to the influence of group size in decision-making, we will see some studies of different fields. But before that, some of the concepts related to groups are explained in this section.

According to many researchers, the individual presents a unique and distinct human being, with different traits of perception, personality, and motivation, so even the behaviour differs from one individual to another (George \& Jones, 2011; Schermerhorn, 2014; Schermerhorn, et al., 2010). On the other hand, the group presents a whole of people who, by their actions and mutual influence on one another, make efforts to perform a task successfully or achieve a purpose (Champoux, 2011; Robbins \& Judge, 2014). While, at the highest level of the pyramid, the organization is located, for which, almost all researchers agree that it presents a structure of positions with different roles and responsibilities; people who perform tasks according to the relevant positions; possess an authority and command chain and a hierarchy of power and control; has a centralization or decentralization level; uses a relevant technology; coordinates tasks and duties among groups of different departments and works (George \& Jones, 2011; Robbins \& Judge, 2014; Schermerhorn, 2014; Schermerhorn, et al., 2010).

The first differences between the group and the team are comprehensively established in theory. So, whilst the group presents a whole of people who coordinate their actions for a mutual goal, the team seems to be a much closer formation, which interacts and one member's activities affect the other members' and vice versa. According to Schermerhorn (2014), a team is a small group of people who performs relevant tasks within the organization, where team members have complementary skills and are responsible in a reciprocal way for their actions. This is supported by Daft (2008), according to whom, the team consists in a group of 2 or more members, who coordinate their actions for a mutual goal, but they do it having a sense of sharing the same mission and collective responsibility. So, the team comes to be a formation in meaning of a very close and tight group of people who have a clear purpose, open communication, participation, informal relationships, reciprocal interactivity, style diversity, and self-assessment (Mealiea \& Baltazar, 2005).

Teams may be large. But their size mainly consists of around 15 members. In a research with manufacturing companies, we can see a decrease of the average number of team members from around 13 people to around 11 (Daft, 2008), which gives us a sign that the decreasing of team members must have a reason behind it.

\section{METHODOLOGY}

The methodology used in this study is an analytical approach toward the existing theories, research, and academic work in relation to group and team size and its effect on decisionmaking. A systematic review of the literature is important in order to synthesize the previous results and critically evaluate them. Despite potential flaws and present debate on 'superior quality', a systematic literature review serves as a useful summarizing meta-study of previous research (Boell \& Cecez-Kecmanovic, 2015). In light of this, following strict rules of finding existing studies, selecting and carefully assessing contributions, synthesizing and analysing findings, this paper will present final conclusions on the debate over the effect of size in decision-making. 
On top of that, based on the final reporting of these discussions, the optimal number of team members that leads to effective decision-making will be explored. This goes beyond a simple systematic literature review as Denyer and Tranfield (2009, p. 686) would say '... reviews in management and organization studies are generally more likely to be interpretive or explanatory rather than aggregative'. Concerning this statement, the paper itself tends to aggregate findings into a more specific result, such as the number of team members, therefore moving beyond a review.

Based on the attributes of a systematic literature review, we have organized the studies using the criteria of 'size' and 'groups' and divided them into different categories called 'perspectives'. Social, cultural, political, religious, educational and - the most important organizational perspectives are representative of the discussions on the effect of group size on different aspects. There were also more perspectives from biology or terrorism, but they were not found to be representative of the main idea and discussion.

Following a more specific path towards the scope of the paper, the discussion is focused on the effect of size on team success. Over and above that, we have gradually come to a small team size and its influence on the effectiveness of decision-making. As stated above, the optimal number of people per team is explored, and it tends to give insights for future researches.

\section{FINDINGS AND DISCUSSIONS}

\subsection{Interdisciplinary views on group size}

\section{Social perspective}

The size of the group and the social effects are tied inextricably. More than half a century ago, the authors Thomas and Fink (1963) have researched on the effects of group size in social aspect. They have found that the size of the group has an impact on group performance, participation distribution, nature of interaction, group organization, group member performance, consensus and conformity, and the members' satisfaction. They go on to claim that "the size of the group is an important variable that needs to be taken into account in any theory of group behaviour."

In 1980, one of the studies on the theory of social psychology, deindividuation, addresses the effect of group size, together with group density, on self-consciousness and disinhibited behaviours. According to this experimental study, increasing the size of the group is associated with the decreasing of self-consciousness (Diener et al., 1980).

A few years later, in one of the experimental studies, Liebrand (1984) addresses the effect of social motives, communication, and group size on behaviour in a N-person multi-stage mixedmotion game. He suggests that social motives such as being altruistic, cooperative, individualist or competitive, along with communication, make the subjects of the experimental game to get more or less from the resources of the goods. Here, Liebrand also analyzes the size of the two different groups in the experiment and brings results that are contrary to predictions based on previous research. According to the results of the experiments in this game, the subjects in the 20-person group did not get more for themselves from the amount of resources than the subjects in the 7-person group. 
Choice behaviour in social dilemmas that are presented in two forms: contributing to a common good and getting from a common resource has been addressed in terms of impact on group size, social identity, and decision framing by Brewer and Kramer (1986). These authors, using the $2 \times 2 \times 2$ experiment, in terms of group size, have come to the conclusion that when the dilemma structure is common to group members, then the size of the group does not have any influence, but this did not happen in the case of public goods. According to their findings, individuals in large groups have taken more than individuals in small groups.

Oliver and Marwell (1988) addressed the paradoxical issue of group size in collective action related to critical mass. Their study consists in criticizing Olson's study of the logic of collective action by finding that the authors mistakenly said earlier that large groups are less likely to support collective action than small groups (Olson, 1965). According to them, the effect of the size of the group is closely related to the cost. If the cost of common goods increases in parallel with the increase in the number of people who share the good, large groups would be less active than small ones. The opposite would happen if the cost of common goods slowly increased or not grow at all. In this case, large groups would be much more active than small groups because they would have more resources and their critical mass would be higher than that of the small groups.

Another interesting study deals with the low status of minorities and high status majorities in self- stereotyping (Simon \& Hamilton, 1994). From the lab experiment, it turns out that low status minorities can boost self-stereotyping in order to protect their social identity. But, according to the same study, members of the high status majorities can directly increase selfstereotyping in order to protect their identity and privileges.

Palla et al. (2007) make comparisons between the evolution of large and small groups. They consider that large groups persist for a longer time if they are able to dynamically change their membership. From this, it results that the ability for internal changes creates a higher adaptability. Small groups behave completely different. They tend to maintain their stability and compactness. It is most likely that this is the result of proximity of small group members and the creation of an internal system of values and beliefs, which excludes changes in the structure.

\section{Cultural perspective}

Culture represents a complex entirety of beliefs, ideas, assumptions, values, and attitudes, which the members of a social group or working team share together. These values and beliefs can change over time, but the main point is to be recognized and linked to the relevant group or team (De Bono et al., 2011). In his study on individualism-collectivism and effects of collaboration in the team, Wagner III (1995), has found that group size influences the level of cooperation. According to his study, the larger the group size, the more the level of cooperation among the group member decreases. So, the relation of these variables is negative and consists on conducted data from 492 college students.

Diversity in small groups is a value. This is proven by a controlled experimental study on ethnic diversity and creativity in small groups by McLeod et al. (1996). The ideas produced by the ethnic diversity were of a higher quality than those of a homogenous group. However, the members of a more compact group showed a higher tendency of attraction to the group than the members of the group with ethnic diversity. But the group size influences the heterogeneity and homogeneity of the group (Richard et al., 2004). Cultural differences enhance with increasing of group size, which serves to an additional heterogeneity. In an opposite case, at small groups we have a more 
emphasized homogeneity, which results in less cultural differences. But, as it is found in DrachZahavy and Somech (2001), the more heterogenic a team is, the more innovation it produces.

Among studies which deal with cultural effect of group size is one of Chung and Adams (1997) who made a cultural comparative analysis on United States and South Korea. When it comes to the group size effect, there is not much difference between the US and South Korea. It might be as a result of an approximately similar technological development, which disproves the Hofstede findings on South Koreans on a low individualism, high power distance, high uncertainty avoiding, and lower masculinity than the Americans. Chung and Adams found that the group size does not differ that much between Americans and South Koreans. The most significant differences can be noticed in the team life as a function of its size and role. They found that teams of departmental meeting, with 16 members at Koreans and 17 at Americans, have a permanent life. But, it is not the same at the task force teams ( 8 at Koreans and 7 at Americans), which have an average life of 8, respectively, 7 months. According to their findings, the projects teams $(10-$ Koreans, 7 - Americans), do not live longer than 11, respectively, 9 months. On the other hand, project committees have an even shorter life. They have an equal size of 9 members as at Koreans, so at Americans, and lasts 4 months in South Korea and 5 in United States.

Citing Kelly, Henrich (2004) explains the effect of group size in the process of expanding and what is known as group selection. The differences and similarities between two tribes, the Nuer and the Dinka, are explained. The Dinka used to live in small tribes, whereas the Nuer used to live in large organized communities and could organize much larger numbers of people. The Nuer, as opposed to the Dinka, were geographically less limited. They could organize the population into wider territories. And this caused a huge invasion in 1820, when the Nuer expanded at the expense of the Dinka and spread their practices all over the Dinka territory by killing, capturing, or even assimilating the Dinka community.

Aiming to study the group size effect on cultural complexity, Derex, et al. (2013) have conducted an experiment with 366 men in a dual-task computer game. According to this study, the difference between groups of 2, 4, 8 and 16 members for probability of maintaining a simple task is not so high. It becomes more obvious when the task is complex. And the more the group size increases, the greater the probability of cultural diversity being maintained.

Group size has a key role in cultural accumulation. In an experiment with 80 participants to complete a jigsaw puzzle, there was no increase in the jigsaw completed puzzles in individual conditions, but it showed a significant increasing in the conditions (Kempe \& Mesoudi, 2014). According to this study, increasing group size consists in transmitting more information among group member, and as a result, more puzzles solved. This study supports previous models (Henrich, 2004) and experiments (Derex, et al., 2013).

\section{Political perspective}

Everyday life is full of politics. So is the individual approach to the world, and as people influence and are influenced by different political currents, they belong to groups with different political backgrounds.

Adrian and Press (1968) treat the influence of group size in group decision making from the perspective of coalitions and come to conclusions that being in a winning coalition does not mean to win, and the other case, losing in a voting process, does not mean you really lost. According to them, it is the size principle, which will dominate the zero-sum. In case of two individuals within a group, the decision should be taken with $100 \%$ of support, while in case of 3 people, with $66 \%$. They also give an example of voting in the United States House of 
Representatives, where with 435 members, decisions can pass with $50.1 \%$ of votes, or 218 Congressmen. So, the power of individuals within small groups is big enough, and information flow is at high levels. By decreasing group size, even the cost of ensuring additional votes decreases (Dixit \& Londregan, 1996).

Group size is also linked to the effectiveness of collective actions. According to a study conducted in 28 forest councils in Kumaon, India, the cost of monitoring by groups will increase proportionally with increasing group size (Agrawal \& Goyal, 2001). In the same study, monitoring technologies do not change with the increasing of groups and common monitoring will be selected mainly by small groups, either because of the low cost, or even because of the effectiveness. By raising the group size, the monitoring complexity will also grow, and additional costs would be caused. But, according to another study on heterogeneity, group size, and collective actions in forest management by institutions, increasing the size of the group does not mean to deteriorate the collective actions (Poteete \& Ostrom, 2004).

Seeing the paradox of Olson, big groups are more inclined to have less success than small groups (Olson, 1965). Oliver and Marwell (1988) oppose this paradox by analysing the critical mass and the cost in the context of social behaviour. Even Esteban and Ray (2001) have found new results. In their study on collective actions and group size paradox, they found that 'when the cost of lobbying has the elasticity of quadratic function, or higher, larger groups are more effective no matter how private the prize is.' It happens when the prize is fully public. However, in an opposite case, the smaller a group is, the more effectiveness it shows. But, they also noticed that when the cost increases sufficiently fast with contributions, yet the larger groups are more effective.

\section{Religious perspective}

Groups are everywhere, and their size effect influences different aspects of life. Some studies which deal with group size effect are strongly related to the religious aspect. An interesting study shows that Catholics are less likely to marry within their dioceses, when they live in small groups, and the opposite happens when they live in large groups in their dioceses (Davidson \& Widman, 2002).

Larger societies are considered to be more stratified, so belief in moralizing gods serves to preserve and keep the economic and political inequality (Norenzayan \& Shariff, 2008). While, at Henrich et al., (2010), Norenzayan and Sharif (2008), and Wright (2009) support it by stating that moralizing religions has a positive relation with community size and complexity. So, the more the society size and complexity increase, the more the moralizing religions become part of the community lifestyle. It is also supported by Norenzayan (2014) in 'Does religion make people moral?' where he considered that when the human intuition about supernatural being began, a fast cultural evolution influenced a coevolution between community size and complexity in one side and the devotion to Big Gods in the other side, which requested an expanding of the group and demanded unwavering commitment and full loyalty.

Group size is also a function of community behaviour in the context of religion (Skribekk et al., 2010). Skribekk et al. (2010) provided a study on religious composition of the United States to 2043. In their study, they found that the size of Hispanic Catholics will grow and expand from $10 \%$ to $18 \%$ of the entire population in the US between 2003 and 2043, and it will be a result of the current fertility and migration trends. Their expansion will affect a decrease of Protestants from $47 \%$ to $39 \%$ during this period. Therefore, the population size is highly influenced by religious behaviour as we see in the case of fertility and migration trends. 


\section{Educational perspective}

Education is considered to be highly influenced by the number of people involved in the process. So, the group size affects it and different scholars and researchers have proven it through a number of studies. When it comes to research productivity, it is found that the size of the group (department or organization) has a positive relation effect, but this effect decreases when the department becomes large (Jordan et al., 1988). Moreover, group size does affect also the achievements and engagement of students in classes (Russ et al., 2001). Russ, et al. found that smaller class sizes lead to higher involvement and suggest an association with an increasing rate of teacher retention.

Louis et al. (2007) found that group size is positively related to early productivity at graduate students and postdoctoral fellows. It is supported by another research that studies the quality of preschool programs, where the maximization of the skills of the students is strongly related to the improvement of classroom quality (Early et al., 2007).

Cooperative learning in groups leads to higher achievements than individualistic learning (Bertucci et al., 2010). Bertucci et al. have also found that students working in pairs of two are more likely to develop self-esteem than all other types of groups. Teams are also more likely to produce and share knowledge than individuals do (Wuchty et al., 2007). In sciences, team size has grown from 1.9 to 3.5 over the past 55 years. When we see the effect of family size on education of their members, Black et al. (2005) found that there is a negative correlation. So, the bigger a family is, the less education its children get.

\section{Organizational perspective}

As teams and decision making are two main components of contemporary organizational processes, it is of a high importance to study the group size effect from this perspective as well. As we saw that group size has a huge influence in different aspects such as the cultural, social, political, religious, or educational ones, we can also say that organization is like a community which is part of society, has a culture, shares beliefs and assumptions, possesses diversity and affects and is affected by education. It makes the organization largely influenced by size.

One of the first studies which deal with group and individual differences is the one of Watson (1928), who found that the product of group is distinctly superior to the one of the average and even the best member of the group. He also concluded that groups between 3 and 10 members are much better at getting higher quality products. Later, Shaw (1932) experimented with groups of 4 people, because he considered that this amount of group members is considered to be optimal for solution of complex problems than smaller or larger groups. It is found that large groups are complicated and they have less consensus, slower on specific and practical problems, but better on abstract problems; the leader has less influence on making a group decision, and results on performance and quality are contradictory (Ziller, 1957). But, when it comes to taking risky decisions, groups are more likely to do that than individuals, and the larger the group is, the more risky decisions they make (Belovicz et al., 1968), because the members share responsibility and as a result they care less about the failure.

A research on brainstorming procedure, group size and sex as determinants of the problem solving by groups and individuals, has proven that group size has an effect when it comes to nominal groups (7-person outperformed 4-person group), but there is no size effect at real groups (Bouchard et al., 1974). Nominal and Delphi groups are considered to be equally effective with a range of 2 to 4 members per team, which even is less than in real life, and is 
quite applicable in many cases (Van De Ven \& Delbecq, 1974). In the same year, Lundgren and Bogart (1974) found that there is a positive correlation between group size and dissatisfaction and at the same time a positive correlation between group size and radicalism. So, the larger a group is, the more dissatisfied are its members, and it is more likely to slide to radicalism. But it is also found that teams consisting of two members are much less satisfied than those consisting of three or four members (Cossé et al., 1999).

It is already known that group decision making on solving problems is quite a complicated process, and especially the relations among group members after the decision are a subject of many studies. Manners (1975) found that group size has an important non-linear effect on two main variables of his study: problem solving effectiveness and post discussion member consensus. Also, the performance is considered to decline when group exceeds five members (Yetton \& Bottger, 1983), but it is higher when the team members have higher abilities than teams with lower skills. According to a study of team size effect on business game performance and decision making behaviours, was found that a three member format of teams produces the highest learning levels, while two member teams only marginally knowledge increase (Wolfe \& Chacko, 1983). Bray et al. (1978) linked the group performance quality with team size and found that the number of 'non-participating' members in a team increases with team size enlargement. They considered that a large team will become more dysfunctional than a small one. With the term 'functional team', they meant a team where all members are collaborative and eager to work together. As dysfunctionality increases with size, another phenomenon known as 'bad apple' is shown, where group members behave in a bad manner and disorder the functionality of the group (Felps et al., 2006).

When we talk about size in organizations, we always bear in mind that organizations are forms of many segments, many units, and subunits. Here we have a research which found that subunit size and performance have no positive relation neither in absolute or relative term, whereas at organizational level, the larger a company is, in absolute terms it performs better, but not in relative terms (Gooding \& Wagnerr III, 1985). For reaching a high performance and productivity, it is considered that the best size of a team would consist of two people, in order to avoid the free-riding and social loafing, but as different projects require more people to deal with different tasks, it seems to be not a good idea (Fried, 1991). Finding an optimal group size is a strong requirement for social dilemma and avoiding motivation loss (Kameda et al., 1992). So, the working group should be sized large enough to accomplish with all assigned tasks, but being too large might lead to dysfunctionality, and that is why the teams should consist of the smallest amount of members which is enough to deal with all tasks (Gladstein, 1984; O'Reilly \& Roberts, 1977). In a research on 47 organizations, it is found that large teams performed better and other companies with CEOs as dominant performed worse in turbulent environment (Haleblian \& Finkelstein, 1993) and this is supported by other studies where team size and group diversity is positively related to effectiveness (Campion et al., 1993; Guzzo \& Dickson, 1996).

In a study of 48 Top Management Teams and cognitive and affective conflicts, it is found that there is a positive relation between team size and openness with cognitive conflict (Amason \& Sapienza, 1997). This also leads to poorer team processes with increasing team size, as is found at Curral et al. (2001). With team processes we talk about cognitive, motivational, and behavioural (Kozlowski \& Ilgen, 2006).

Another study which examines relationship between reward structure and team performance, where 75 teams of four people, was found that teams with a higher number of extroverted 
members perform better under cooperative structure, while those who have more introverted people perform better under competitive conditions (Beersma et al., 2003). It is also found that if production can be doubled in manufacturing companies, the team size can be halved.

There is not an optimal size of teams, but companies must determine team size according to the size of tasks, the requirements of team members, and project complexity (Hoegl et al., 2003). Herein the larger a project gets, the more members must be added in a team, in order to increase skills and experiences diversity to deal easily with more complex tasks. Hoegl (2005) considered that small teams have higher chances to be more successful than larger teams. In a study in 2005, he compared teams of 3-6 and those of 7-9 and according to his findings, at smaller teams were noticed a higher teamwork quality, a much better communication, coordination, cohesion, efforts, higher mutual support, and balance of contributions than at those of 7-9 members. On the other hand, team size is negatively correlated with the quality of group experience, which leads to counterproductive behaviours (Aubé et al., 2011). Pearce and Herbik (2004) found in a study by examining 71 change teams management that team size has a small-to-negligible effect on citizenship behaviour.

There are also studies which deal with team size effect on mobile learning (Schwabe et al., 2005). Schwabe et al. (2005) have found that even mobile applications favour individuals rather than teams, there are still findings that prove more effectiveness by teams comparing to individuals. They found that teams of two are more effective, and by increasing team size to four, fun, immersion, and learning decrease.

There are findings which prove that team size has a positive correlation with team output, but output increases till a moment when marginal cost of adding additional members exceeds marginal profit (Tohidi \& Tarokh, 2006), so when the cost is positive and marginally not decreasing, then we can say that we have an optimal team size. However, it needs to be supported by communication and technology changes in order to keep high output production.

Liang et al. (2008) found that team sizes will be higher and quality of members will be unchanged or lower in setting with relatively lower levels of uncertainty and/or better technology for measuring performance. But not only! Work-group size is considered to be a key factor in determining the development and the productivity of group (Wheelan, 2009). Wheelan studied 329 work groups in for-profit and non-profit organizations in the United States and found that groups of 3-8 members were more productive than those of 9 or more members. Also groups of 36 members were much more productive and developmentally advanced than those of 7-10 or 11 members or more. Groups of 7-10 members did not differ much from those of 11 members or more, and finally groups consisting of 3 to 4 members were much more productive and developmentally advanced than groups with 5 to 6 members.

Team size has different effects, and one of them is social loafing, known as the tendency of individuals to exert less effort to deal with a task when they work in group versus when they work individually. Alnuaimi et al. (2010) found that members of technology-supported teams become more inclined to make negative attributions with team size increasing. According to their findings, members of large-sized teams attribute their loafing to other members more than members of small-sized teams.

There are findings that show correlation between team size, efforts, and productivity, but statistical results are not always as expected from literature or intuition. For example, in software development projects, teams of 9 or more members are less productive than those 
who exceed this threshold as suggested by literature (Rodríguez et al., 2012). Absolute team size can lead to over-staffing or understaffing, so it is considered to use a relative team size instead of an absolute one. Weiss and Hoegl (2015) found that team size has an important effect in teams with innovative tasks, so they suggest not use a small size, neither a large one, but to find an optimal average depending on pressure and tasks diversity. Finally, one of the most important factors in team success is flexibility. But when it comes to the relationship between team size and flexibility, it is found that large teams lead to less flexibility and more individual differences within the team (Salas, et al., 2017).

\subsection{Size as an incentive for team success}

As we saw from many studies from different perspectives, size plays a crucial role in team success or failure. Some studies have considered that the smaller the teams, the more likely they are to succeed their goals (Manners, 1975; Shaw, 1932; Wolfe \& Chacko, 1983; Yetton \& Bottger, 1983). Large teams take more risky decisions, and at same time their dissatisfaction increases (Belovicz et al., 1968; Lundgren \& Bogart, 1974). There are some aspects of team success that are influenced by team size.

Comparing groups to individuals, it is found that groups are more productive and they can produce higher quality products (Watson, 1928) than individuals can do. It means that the size of a group is larger than that of individuals. It might consist of two or more people who work together with reciprocal responsibility for the same goal. Size is considered to be a key factor in development and productivity of teams (Wheelan, 2009), because a small size of a team has other effects than a large one, and both have different results on team success. For example, it is considered that increasing team size, the quality of group experience will decrease and at same time counterproductive behaviours will increase (Aubé et al., 2011). It is strongly related to team success, because it seems that large team size will influence negatively the experience and, even a study found that size does have a small-to-ngelible effect on citizenship behaviour (Pearce \& Herbik, 2004), it will cause such behaviours which will reflect negatively on productivity.

When Ziller (1957) stated that large groups have contradictory performance and quality, discussed about the diversity of people consisting in the group, which includes perspectives from different personalities, with different experiences, knowledge, and skills. But, according to Campion (1993) and Guzzo with Dickson (1996), team size and diversity have a positive correlation to effectiveness, which means that the larger a team is and the more diversity it has, the more effective it will be in dealing with different tasks, and as a result, it will succeed easier.

But, in order to be a successful team, managers should know other traits of people composing the relevant team. For example, in a team, the larger is the number of extroverted people, the manager must apply a cooperation structure, while they should apply a competitive structure when the size of introverted members is larger as stated in Beersma (2003). On the other hand, when it comes to numbers, most of the authors considered that small teams in general are more effective and successful than the large ones. At large teams, performance declines when size exceeds five members (Yetton \& Bottger, 1983), dysfunctionality increases (Bray et al., 1978), motivation looses (Kameda et al., 1992), while social loafing and free riding are noticed once size exceeds two people (Fried, 1991) and there are even some cases when in large teams, members attribute loafing to their colleagues (Alnuaimi et al., 2010). 
There is also a theoretical suggestion for a team threshold size of 9 members, which was found to be unstable for all cases and shows contradictory between reality and theory (Rodríguez et al., 2012). So, Wheelan (2009) found that teams of 3-6 members are more successful than those of 7-10 or more people. Also on another study where have been compared teams of 3-6 and 7-9 members, it was found that the small teams were more likely to be successful than large ones (Hoegl, 2005).

There is not an optimal size for all possible teams (Hoegl et al., 2003), but according to the tasks assigned, there should be evaluated and used the smallest possible size to deal with tasks (Gladstein, 1984; O'Reilly \& Roberts, 1977), to avoid social dilemma and motivational loss (Kameda et al., 1992), to manage cognitive and affective conflict (Amason \& Sapienza, 1997), to decrease the probability of having 'nonparticipating' members (Bray et al., 1978), increase and keep flexibility in high-enough levels (Salas et al., 2017), increase team work, communication, coordination, cohession, efforts, mutual support, and balance of contribution (Hoegl, 2005).

Teams, to be successful must be small enough to grow output more than marginal cost (Tohidi \& Tarokh, 2006). It means that a team will be successful till a moment when marginal costs overcome the marginal output. Then the cost will be higher than the output for each additional member, which will result in losses and less success.

\subsection{Effectiveness of small teams in decision-making}

Many organizations today operate on a team basis. They create teams to deal with different projects and programs, in order to achieve goals easier and delegate authority and responsibility to lower positions. Some authors have considered that the best team should consist of two people in order to avoid social-loafing (Fried, 1991) and motivation loss (Kameda et al., 1992). While others are more general in evaluating the size by considering that it should be small, but large enough to deal with all assigned tasks (Gladstein, 1984; O'Reilly \& Roberts, 1977).

\section{Defining decision-making}

Group decision-making research during the 1960s and 1970s mainly emphasized the process involved in moving from a diverse of individual preferences to agreement on group choice consensus. According to Kerr and Tindale, 'a simply majority process tends to allow groups to perform better than individuals (reach more optimal solutions, make fewer errors, etc.) typically because most individuals will more often favor the correct or better alternative.' (Kerr \& Tindale, 2004).

Good managers do not make many decisions. They make the right decisions for the right problems. They know when a decision is necessary and they make efforts to avoid making wrong decisions, because those would cause more dangerous problems in the future (Drucker, 1974). The decision-making process is much more than just choosing one among the alternatives. It is a very dynamic process and changes at any moment (Champoux, 2011).

Decision-making represents a process of reaction to a problem, which consists of a distinction between current state of affairs and the desired one (Robbins \& Judge, 2014). Ultimately, decision-making is choosing ONE alternative among two or more options (Griffin \& Moorhead, 2014). But nowadays decisions are made more frequently by groups and teams in different organizations (George \& Jones, 2011). 


\section{Effectiveness of teams}

When it comes to team effectiveness, it is considered when the team has a high performance, at the same time its members feel satisfied and team viabilty lasts longer (Schermerhorn et al., 2010). Tannenbaum, Beard, and Salas (1992, as cited in Goodwin, et al., 2009) proposed a complex model of team effectiveness, which includes six processes: communication, coordination, decision-making, problem solving, conflict resolution, and boundary spanning. So, effectiveness presents the ability of a team to succeed with its tasks, to have member satisfaction, a long life, and to reach it, the team must communicate, make decisions, solve problems, span boundaries, manage conflict and coordinate.

\section{Team size effect on decision-making: the smaller - the more effective}

We have already seen the effects of group size in different aspects, and we have also given a short analysis of some of the most important findings from organizational perspective on group size effects in Chapter 2. In this chapter, after explaining and defining decision-making and team effectiveness, the author has analysed how team size influences the team effectiveness in decision making.

First, let us consider some advantages and disadvantages of group decision-making (George \& Jones, 2011), which leads to more or less successful decisions:

Table 1. Advantages and disadvantages of group decision-making

\begin{tabular}{ll}
\hline Advantages & Disadvantages \\
\hline Availability and diversity & Time to make a decision \\
Enhanced memory for facts & Potential for groupthink \\
Greater ability & Diffusion of responsibility \\
Greater decision acceptance & Group polarization \\
& Potential for conflict \\
\hline
\end{tabular}

Source: Adapted from George and Jones (2011, pp. 449-453)

As it is said before, diversity in small teams is a value which contributes to team processes. Team size is positively correlated with diversity (Campion et al., 1993; Guzzo \& Dickson, 1996), which means that in large groups we have more people, which results in more diverse personalities. They contribute to team processes with more ideas and creative solutions to problems. But high diversity can also lead to group polarization, and teams in such situations are less likely to make decisions by consensus. They are also a good source of facts and experiences, as long as we keep the team small. Aubé et al. (2011) found that team experience quality decreases with increasing team size, even there is enough diversity among members to create a mix of knowledge, skills, and experiences. On the other hand, small teams have more homogeneity, which might lead to potential for groupthink and less ideas for creative solutions.

Shaw (1932) considered that groups of 4 people are quite effective in dealing with problem solution and making decisions. Larger groups are more complicated and ineffective, they have less consensus and are much slower in giving solutions to practical problems (Ziller, 1957), that makes them to lack on fast decision-making when it is necessary.

Decision-making process is always risky because of uncertainties and the approach of the individuals and teams to make decisions. Because of sharing responsibility, known as diffusion of responsibility among team members, groups are more likely to make risky decisions than individuals (Belovicz et al., 1968), which many times leads to great successes or disastrous failures. To avoid risky decisions, the team should comprise the least possible amount of members with different backgrounds who can deal with all team processes. 
Nominal and Delphi groups are good examples of keeping teams small and effective at the same time by having a range of 2 to 4 members per team (Van De Ven \& Delbecq, 1974), which is quite enough to make qualitative decisions and avoid problems as mentioned above. The engagement of all team members in decision-making will lead to more qualitative decisions. But, dissatisfied members will not contribute normally, or even worse, their contribution will be against positive development of team processes. Dissatisfaction among team members is positively correlated with team size (Lundgren \& Bogart, 1974), so keeping teams small will lead to more satisfied members (Cossé et al., 1999), and as a result, team effectiveness in decision-making will reach higher levels.

Team size has a non-linear effect on problem solving effectiveness (Manners, 1975) and adding the performance as an additional variable, we can see that when team reaches a size of 5 members, it starts declining (Yetton \& Bottger, 1983) in performance of making decisions and giving solutions to problems. But, even very small teams consisting of two members are not optimal for decision-making. Three members produce the highest knowledge level, while two members increase knowledge marginally only (Wolfe \& Chacko, 1983). Fried (1991) supports the idea of having two-member teams to avoid free-riding and social loafing, but as different projects require more diverse skills and abilities, then a two-member team would not contribute to qualitative decision-making and project would be less likely to succeed.

Large teams show more dysfunctionality in decision-making, as the number of 'nonparticipating' members (Bray et al., 1978) and 'bad apples' increases with team size (Felps et al., 2006). So, teams should be small enough to accomplish with all tasks, but not that large to overcome the necessities (Gladstein, 1984; O'Reilly \& Roberts, 1977).

Keeping team size small should also be considered when it comes to team conflict (Amason \& Sapienza, 1997) and processes (Curral et al., 2001; Kozlowski \& Ilgen, 2006). These are strongly related to effectiveness, as the cognitive and affective conflict may lead to dissatisfaction and poorer team processes, including decision-making.

There is no optimal team size (Hoegl et al., 2003) in decision-making, but an optimal one would be defined according to project requirement and it is considered that teams consisting of 3-6 members (Hoegl, 2005; Wheelan, 2009) are more effective than those consisting of more than 7 members. So, with teams of this size, decision-making would be a qualitative process, fast, and not lacking in creative ideas for problem solutions. It will also contribute to a higher level of flexibility in making decisions (Salas et al., 2017) and more effectiveness on teams with innovative tasks (Weiss \& Hoegl, 2015).

\section{CONCLUSIONS}

Human existence has seen rapid development, especially in the recent era. This has been proven since people began working closely in groups to achieve different goals. But, as we saw in this paper, scientific studies on group dynamics have been published recently. Many authors that studied group dynamics and processes came to a common conclusion that groups work together for a common purpose.

One of the main factors which have multidimensional effects in group work is the size. Group size affects all aspects of group, including the way the group works, the way the members cooperate, communicate, deal with conflict, make decisions, share responsibility, and more. There exists no consistency on the optimal number of group size for general success. In this 
context, the size of a successful group does not necessarily apply to the other. Basically, considering the different settings and complexities of group work, no generalization can be made on the group size.

However, some scholars found and agree that there are some similar cases where an approximate number of people work better. When it comes to team size effectiveness, productivity reaches higher level with the increasing of the size, but it does not last forever. There is a point when team size and effectiveness do not have any correlation and beyond that point, when the size of the team, effectiveness even starts decreasing. And voila, no qualitative decision-making!

Reasons behind the non-effectiveness of big teams on decision-making are mostly related to time consumption, dysfunctional conflict, heterogeneity and cultural clashes, decrease of responsibility, groupthink, free-riding, and social loafing. Therefore, these are some of the reasons managers should take into consideration when designing teams. However, if the complexity and volume of the task is high, a small team may make a fast decision, but not necessarily effective. More perspectives, different professional approaches, variety of skills and analytical competencies, information processing, on-going feedback, and a broader acceptance are all necessary to come with a final effective decision.

Team size is definitely a relative issue. It differs from one organization to another, and from one task to another, from one culture to another. Huge teams and groups who have full access to all possible resources of finances, information and may even have the time of the world, they would still make non-effective decisions. Therefore, different approaches - such as the heuristics - towards decision-making suggest that individuals, teams, groups, and organizations can make effective decisions relying only on some of the resources, but using them for the best.

In light of the findings discussed in this paper, it is suggested that a number of five members per team may represent a closely-to-optimal team size. Stakeholders in different organizations, especially team managers, should bear this in mind when designing teams, setting goals, assigning tasks, scheduling activities, and following-up the whole process of team work. Those who aim for effectiveness should consider the fact that more does not necessarily mean better. In fact, it might lead to problems, dysfunctionalities, and even a general failure of the team in accomplishing the goal.

This paper recommends future research on further exploring empirically teams in the spectre of size and decision-making, in different settings and different tasks. This would help create a better idea and clear the smoke for academicians and managers in different fields, leading to establishing productive teams and performing better in general, not only in making effective decisions.

\section{ACKNOWLEDGMENT}

This study was conducted in 2017 as a requirement to complete Bachelor studies at the University of Prishtina, Republic of Kosovo, in the field of Management. It has been partially revised in 2021. Hereby, I am grateful for their support to Prof. Dr. Besnik Krasniqi (besnik.krasniqi@uni-edu.pr), who was in charge as a scientific supervisor, and Prof. Dr. Gentrit Berisha (gentrit.berisha@uni-pr.edu), who was and is the biggest critic of my scientific work, helping me grow stronger. 


\section{REFERENCES}

Adrian, C.R., \& Press, C. (1968). Decision Costs in Coalition Formation. American Political Science Review, 62(2), 556-563.

Agrawal, A., \& Goyal, S. (2001). Group Size and Collective Action - Third-Party Monitoring in Common-Pool Resources. Comparative Political Studies, 34(1), 63-93.

Alnuaimi, O.A., Robert Jr., L.P., \& Maruping, L. M. (2010). Team Size, Dispersion, and Social Loafing in Technology-Supported Teams: A Perspective on the Theory of Moral Disengagement. Journal of Management Information Systems, 27(1), 203-230.

Amason, A.C., \& Sapienza, H.J. (1997). The Effects of Top Management Team Size and Interaction Norms on Cognitive and Affective Conflict. Journal of Management, 23(4), 495-516.

Aubé, C., Rousseau, V., \& Tremblay, S. (2011). Team Size and Quality of Group Experience: The More the Merrier?. Group Dynamics: Theory, Research, and Practice, 15(4), 357-375.

Avdiaj, B.S. (2017). New Criminal Occurrences in Kosovar Society: Anthropological and Criminological Overview in Gjakova Region (1999-2012), Tirana: European University of Tirana.

Beersma, B., Hollenbeck, J.R., Humphrey, S.E., Moon, H., Conlon, D.E., \& Ilgen, D.R. (2003). Cooperation, Competition, and Team Performance: Toward a Contingency Approach. The Academy of Management Journal, 46(5), 572-590.

Belovicz, M.W., Finch, F.E., \& Jones, H. (1968). Do Groups Make Riskier Decisions Than Individuals. New York, New York University.

Bertucci, A., Conte, S., Johnson, D.W., \& Johnson, R.T. (2010). The Impact of Size of Cooperative Group on Achievement, Scial Support, and Self-Esteem. The Journal of General Psychology, 137(3), 256-272.

Black, S.E., Devereux, P.G., \& Salvaes, K.G. (2005). The more the merrier? The effect of family size and birth order on children's education. Quarterly Journal of Economics, 120(2), 669-701.

Boell, S.L., \& Cecez-Kecmanovic, D. (2015). On being 'systematic' in literature reviews. In L. P. Willcocks, C. Sauer, \& M. C. Lacity (Eds.), Formulating Research Methods for Information Systems: 2 (pp. 48-78). London: Palgrave Macmillan UK.

Bouchard, J.T.J., Barsaloux, J., \& Drauden, G. (1974). Brainstorming procedure, group size, and sex as determinants of the problem-solving effectiveness of groups and individuals. Journal of Applied Psychology, 59(2), 135-138.

Bray, R.M., Kerr, N.L., \& Atkin, R.S. (1978). Effects of group size, problem difficulty, and sex on group performance and member reactions. Journal of Personality and Social Psychology, 36(11), 1224-1240.

Brewer, M.B., \& Kramer, R.M. (1986). Choice behavior in social dilemmas: Effects of social identity, group size, and decision framing. Journal of personality and social psychology, 50(3), 543.

Campion, M.A., Medsker, G.J., \& Higgs, A.C. (1993). Relations between work group characteristics and effectiveness: Implications for designing effective work groups. Personnel Psychology, 46(4), 823-847.

Champoux, J. (2011). Organizational Behavior: Integrating Individuals, Groups, and Organizations. 4th ed. Abingdon, Oxon: Taylor\&Francis. 
Chung, I.K., \& Adams, C.R. (1997). A Study on the Characteristics of Group Decision Making Behavior: Cultural Difference Perspective of Korea vs. U.S.. Journal of Global Information Management, 5(3), 18-30.

Cossé, T.J., Ashwordh, D.N., \& Wisenberger, T.M. (1999). The Effects of Team Size in a Marketing Simulation. Journal of Marketing Theory and Practice, 7(3), 98-106.

Curral, L.A., Forrestes, R.H., Dawson, J.F., \& West, M.A. (2001). It's what you do and the way tha you do it: Team task, team size, and innovation-related group processes. European Journal of Work and Organizational Psychology, 10(2), 187-204.

Daft, R.L. (2008). Management. 8th ed. Ohio: Thompson Higher Education.

Davidson, J.D., \& Widman, T. (2002). The Effect of Group Size on Interfaith Marriage Among Catholics. Journal for the Scienfitic Study of Religion, 41(3), 397-404.

De Bono, S., Jones, S., \& Van der Heijden, B. (2011). Managing Cultural Diversity. 2nd ed. Maidenhead: Mayer \& Mayer Ltd.

Denyer, D., \& Tranfield, D. (2009). Producing a systematic review The Sage handbook of organizational research methods. (pp. 671-689). Thousand Oaks, CA: Sage Publications Ltd.

Derex, M., Beugin, M.P., Godelle, B., \& Raymond, M. (2013). Experimental evidence for the influence of group size on cultural complexity. Nature International weekly journal of science, 21 November, 389-391.

Diener, E., Lusk, R., DeFour, D., \& Flax, R. (1980). Deindividuation: Effects of Group Size, Density, Number of Observers, and Group Member Similarity on Self-Consciousness and Disinhibited Behavior. Journal of Personality and Social Psychology, 39(3), 449-459.

Dixit, A., \& Londregan, J. (1996). The Determinants of Success of Special Interests in Redistributive Politics. The Journal of Politics, 58(4), 1132-1155.

Drach-Zahavy, A., \& Somech, A. (2001). Understanding Team Innovation: The Role of Team Processes and Structures. Group Dynamics: Theory, Research, and Practice, 5(2), 111-123.

Drucker, P. (1974). Management. 1st ed. New York: Harper \& Row.

Early, D.M., Maxwell, K.L., Burchinal, M., Alva, S., Bender, R.H., Bryant, D. et al. (2007). Teachers' Education, Classroom Quality, and Young Children's Academic Skills: Results from Seven Studies of Preschool Programs. Child Development, 78(2), 558-580.

Esteban, J., \& Ray, D. (2001). Collective Action and the Group Size Paradox. American Political Science Review, 95(3), 663-672.

Felps, W., Mitchell, T.R., \& Byington, E. (2006). How, when, and why bad apples spoil the barrel: Negative group members and dysfunctional groups. Research in Organizational Behavior, 27(1), 175-222.

Fried, L. (1991). Team size and productivity in systems development - Bigger Does not Always Mean Better. Journal of Information Systems Management, 8(3), 27-35.

George, J.M., \& Jones, G.R. (2011). Understanding and Managing Organizational Behavior. 6th ed. New Jersey: Prentice Hall.

Gladstein, D.L. (1984). Groups in Context: A Model of Task Group Effectiveness. Administrative Science Quarterly, 29(4), 499-517.

Gooding, R.Z., \& Wagnerr III, J.A. (1985). A Meta-Analytic Review of the Relationship between Size and Performance: The Productivity and Efficiency of Organizations and Their Subunits. Administrative Science Quarterly, 30(4), 462-481.

Goodwin, G.F., Burke, C.S., Wildman, J.L., \& Salas, E. (2009). Team Effectiveness in Complex Organizations: An Overview. In: R. D. Pritchard, ed. Team Effectiveness in Complex 
Organizations - Cross-Disciplinary Perspectives and Approaches. New York: Taylor \& Francis Group, 3-16.

Griffin, R.W., \& Moorhead, G. (2014). Organizational Behavior - Managing People and Organizations. 11th ed. Mason: Cengage Learning.

Guzzo, R.A. \& Dickson, M.W. (1996). Teams in organizations: Recent Research on Performance and Effectiveness. Annual Review of Psychology, 47(1), 307-338.

Haleblian, J., \& Finkelstein, S. (1993). Top Management Team Size, CEO Dominance, and Firm Performance: The Moderating Roles of Environmental Turbulence and Discretion. The Academy of Management Journal, 36(4), 844-863.

Henrich, J. (2004). Cultural group selection, coevolutionary processes and large-scale cooperation. Journal of Economic Behavior \& Organization, 53(1), 3-35.

Henrich, J., Heine, S.J., \& Norenzayan, A. (2010). The weirdest people in the world? Behavioral and brain sciences, 33(2-3), 61-83.

Hoegl, M. (2005). Smaller teams-better teamwork: How to keep project teams small. Business Horizons, 48, 209-214.

Hoegl, M., Parboteeah, K.P., \& Gemuenden, H.G. (2003). When teamwork really matters: task innovativeness as a moderator of the teamwork-performance relationship in software development projects. Journal of Engineering and Technology Management, 20(4), 281-302.

Jordan, J.M., Meador, M., \& Walters, S.J. (1988). Effects of Department Size and Organization on the Research Productivity of Academic Economists. Economics of Education Review, 7(2), 251-255.

Kameda, T., Stasson, M.F., Davis, J.H., Parks, C.D., \& Zimmerman, S.K. (1992). Social Dilemmas, Subgroups, and Motivation Loss in Task-Oriented Groups: In Search of an "Optimal" Team Size in Division of Work. Social Psychology Quarterly, 55(1), 47-56.

Kempe, M., \& Mesoudi, A. (2014). An experimental demonstration of the effect of group size on cultural accumulation. Evolution and Human Behavior, 35(4), 285-290.

Kerr, N.L., \& Tindale, R.S. (2004). Group Performance and Decision Making. Annual Review of Psychology, 55, 623-655.

Kozlowski, S.W., \& Ilgen, D.R. (2006). Enhancing the Effectiveness of Work Groups and Teams. Psychological Science in the Public Interest, 7(3), 77-124.

Liang, P.J., Rajan, M.V., \& Ray, K. (2008). Optimal Team Size and Monitoring in Organizations. The Accounting Review, 83(3), 789-822.

Liebrand, W.B.G. (1984). The effect of social motives, communication and group size on behaviour in an N-person multi-stage mixed-motive game. European Journal of Social Psychology, 14(3), 239-264.

Louis, K.S., Holdsworth, J.M., Anderson, M.S., \& Campbell, E.G. (2007). Becoming a Scientist: The Effects of Work-Group Size and Organizational Climate. The Journal of Higher Education, 78(3), 311-336.

Lundgren, D.C., \& Bogart, D.H. (1974). Group Size, Member Dissatisfaction, and Group Radicalism. Human Relations, 27(4), 339-355.

Manners, J.G.E. (1975). Another Look at Group Size, Group Problem Solving, and Member Consensus. The Academy of Management Journal, 18(4), 715-724.

McLeod, P.L., Lobel, S.A., \& Cox, J.T.H. (1996). Ethnic Diversity and Creativity in Small Groups. Small Group Research, 27(2), 248-264. 
Mealiea, L., \& Baltazar, R. (2005). A Strategic Guide for Building Effective Teams. Public Personnel Management, 34(2), 141-160.

Norenzayan, A., \& Shariff, A.F. (2008). The Origin and Evolution of Religious Prosociality. Science, 322(5898), 58-62.

Norenzayan, A. (2014). Does religion make people moral?. Behaviour, 151(2-3), 365-384.

Oliver, P.E., \& Marwell, G. (1988). The Paradox of Group Size in Collective Action: A Theory of the Critical Mass. II.. American Sociological Review, 53(1), 1-8.

Olson, M. (1965). The Logic of collective action: public goods and the Theory of Groups. 1st ed. Massachusetts: Harvard University Press.

O'Reilly, C.A., \& Roberts, K.H. (1977). Task group structure, communication and effectiveness in three organizations. Journal of Applied Psychology, 62(6), 674-681.

Palla, G., Barabáasi, A.-L., \& Vicsek, T. (2007). Quantifying social group evolution. International weekly journal of science, 446(1), 664-667.

Pearce, C.L., \& Herbik, P.A. (2004). Citizenship Behavior at the Team Level of Analysis: The Effects of Team Leadership, Team Commitment, Perceived Team Support, and Team Size. The Journal of Social Psychology, 144(3), 293-310.

Poteete, A.R., \& Ostrom, E. (2004). Heterogeneity, Group Size and Collective Action: The Role of Institutions in Forest Management. Development and Change, 35(3), 435-461.

Richard, O.C., Barnett, T., Dwyer, S., \& Chadwick, K. (2004). Cultural Diversity in Management, Firm Performance, and the Moderating Role of Entrepreneurial Orientation Dimensions. The Academy of Management Journal, 47(2), 255-266.

Robbins, S.P., \& Judge, T.A. (2014). Essentials of Organizational Behavior. 12th ed. New Jersey: Pearson Education.

Rodríguez, D., Sicilia, M.Á., García-Barriocanal, E., \& Harrison, R. (2012). Empirical findings on team size and productivity in software development. The Journal of Systems and Software, $85(3), 562-570$.

Russ, S., Chiang, B., Rylance, B., \& Bongers, J. (2001). Caseload in Special Education: An Integration of Research Findings. Exceptional Children, 67(2), 161-172.

Salas, E., Reyes, D.L., \& Woods, A.I. (2017). The Assesssment of Team Performance: Observations and Needs. In: A. A. von Davier, M. Zhu \& P. C. Kyllonen, eds. Innovative Assessment of Collaboration. Zürich: Springer International Publishing Switzerland 2017, 21-36.

Schermerhorn, J.J.R. (2014). Exploring Management. 4th ed. New Jersey: John Wiley \& Sons, Inc.

Schermerhorn, J.J.R., Hunt, J.G., Osborn, R.N., \& Uhl-Bien, M. (2010). Organizational Behavior. New Jersey: John Wiley \& Sons, Inc..

Schwabe, G., Göth, C., \& Frohberg, D. (2005). Does Team Size Matter in Mobile Learning?. Washington, IEEE Computer Society Washington, 227-234.

Shaw, M.E. (1932). A Comparison of Individuals and Small Groups in the Rational Solution of Complext Problems. The American Journal of Psychology, 44(3), pp. 491-504.

Simon, B., \& Hamilton, D.L. (1994). Self-Stereotyping and Social Context: The Effects of Relative In-Group Size and In-Group Status. Journal of Personality and Social Psychology, 66(4), 699-711.

Skribekk, V., Kaufman, E., \& Goujon, A. (2010). Secularism, Fundamentalism, or Catholicism? The Religious Composition of the United States to 2043. Journal for the Scientific Study of Religion, 49(2), 293-310. 
Thomas, E.J., \& Fink, C.F. (1963). Effects of Group Size. Pyschological Bulletin, 60(4), 371-384.

Tohidi, H., \& Tarokh, M.J. (2006). Productivity outcomes of teamwork as an effect of information technology and team size. International Journal of Production Economics, 103(2), 610-615.

Van De Ven, A.H., \& Delbecq, A. (1974). The Effectiveness of Nominal, Delphi, and Interacting Group Decision Making Processes. The Academy of Management Journal, $17(4), 605-621$.

Wagner III, J.A. (1995). Studies of Individualism-Collectivism: Effects on Cooperation in Groups. The Academy of Management Journal, 38(1), 152-172.

Watson, G.B. (1928). Do Groups Think More Efficiently Than Individuals?. The Journal of Abnormal and Social Psychology, 23(3), pp. 328-336.

Weiss, M., \& Hoegl, M. (2015). Effects of relative team size on teams with innovative tasks: An understaffing theory perspective. Organizational Psychology Review, 6(4), 324-351.

Wheelan, S.A. (2009). Group Size, Group Development, and Group Productivity. Small Group Research, 40(2), 247-262.

Wolfe, J., \& Chacko, T.I. (1983). Team-size effects on business game performance and decision-making behaviors. Decision Sciences, 14(1), 121-133.

Wright, R. (2009). The Evolution of God. 1st ed. Little: Brown and Company.

Wuchty, S., Jones, B.F., \& Uzzi, B. (2007). The Increasing Dominance of Teams in Production of Knowledge. Science, 316(5827), 1036-1039.

Yetton, P., \& Bottger, P. (1983). The Relationships among Group Size, Member Ability, Social Decision Schemes, and Performance. Organizational Behavior and Human Performance, 32(2), 145-159.

Ziller, R.C. (1957). Group Size: A Determinant of the Quality and Stability of Group Decisions. Sociometry, 20(2), 165-173. 